taken a massive overdose compatible with the stated amount. Assessing drug toxicity in overdosage is also complicated by the frequent occurrence of multiple drug overdoses. Thus negative results from a comprehensive toxicological screen, ${ }^{4}$ as in cases $2,3,5$, and 7 , are important to establish that the symptoms observed are due to the alleged overdose.

Illingworth and Prescott ${ }^{5}$ recently reviewed the information on drug overdosage in manufacturers' data sheets and concluded that the information provided was often inadequate and sometimes inaccurate. We believe that our report shows that co-operation between the National Poisons Information Service and manufacturers can be an important factor in correcting these shortcomings.

We thank the many doctors who helped to collect these data and Sandoz Limited, UK and Basle, for their co-operation.

${ }^{1}$ Gazzard BG, Davis M, Spooner JB, Williams RS. Why paracetamol ? F Int Med Res 1976;4, suppl 4:25-8.

${ }^{2}$ Perhaj Z, Laplanche R. Documenta Sandoz. Basle: Sandoz, March 1979.

${ }^{3}$ Goulding R, Volans GN. Poisons information services. In: Inman WHW, ed. Monitoring for drug safety. London: MTP Press, 1980:367-77.

${ }^{4}$ Helliwell M, Hampel G, Sinclair E, Hugget A, Flanagan RJ. Value of emergency toxicological investigations in differential diagnosis of coma. Br Med F 1979; ;i :819-21.

${ }^{5}$ Illingworth RN, Prescott LF. Inadequate information about drug overdosage in manufacturers' data sheets. Br Med f 1980;280:1418.

(Accepted 13 March 1981)

National Poisons Information Service, Guy's Hospital, London SE1 9RT

D B JEFFERYS, BSC, MRCP, registrar

G N VOLANS, MD, MRCP, director

\section{Persistent involuntary movements after treatment with flupenthixol}

Flupenthixol decanoate, a thioxanthene derivative chemically similar to the phenothiazines, is a depot neuroleptic used in the treatment of psychosis. We describe a patient who developed intractable, involuntary movements after treatment with this drug.

\section{Case report}

A 17-year-old boy developed a paranoid psychosis with auditory hallucinations and was admitted to psychiatric care in May 1979. He had been a fullterm, low-cavity forceps delivery and had had normal milestones and average scholastic ability. A febrile convulsion at age 3 had been followed by several major fits during the next year. From then until this admission he had been treated with phenytoin and had no further seizures. There was no family history of neurological disease, and physical examination was normal. Treatment was started with chlorpromazine $300 \mathrm{mg}$ daily and electric convulsion therapy. He made a good recovery and was discharged, but was re-admitted in August 1979 with a relapse. Treatment was started with depot flupenthixol alone $40 \mathrm{mg}$ monthly.

Three months later his mother noticed that he was walking on the outside of his feet. After discharge in January 1980 this became more pronounced and he developed in addition involuntary limb jerking and dystonic hyperextension of the neck and trunk. These involuntary movements started after each injection and lasted for about two weeks. A period of normal motor activity then followed until the next injection. This symptom-free period gradually shortened until the movements were continually present. A total of $360 \mathrm{mg}$ flupenthixol was administered over a nine-month period. His condition did not improve on stopping treatment, despite anticholinergics being given, and he was transferred to the neurological unit in June 1980.

On examination he was found to have severe, continuous movements of neck, trunk, and limbs, with spasmodic myoclonic jerking of arms and legs. He was sweating profusely, feverish, unable to sit or stand unaided, and had to be fed. No other abnormality was evident. Serological and copper studies yielded negative results, and cerebrospinal fluid, a computed tomogram, and an electroencephalogram were normal. Limb myoclonus improved on administration of intravenous clonazepam, and oral treatment with $3 \mathrm{mg}$ thrice daily was started. Neither this, nor the subsequent introduction of pimozide, had any effect on the dystonic movements. Over six months he improved sufficiently to walk unaided. Dystonic posturing of neck and trunk persisted, however, particularly on exercise.

\section{Comment}

Dystonia as a side effect of neuroleptic medication is most often seen in young people. ${ }^{1}$ It usually occurs during the first week of treatment and responds to anticholinergics and withdrawal of the drug. Neurological sequelae to accidental tranquilliser overdosage in children are seen more often in those with an abnormal birth history or who had childhood convulsions. ${ }^{2}$ Persistent dystonia after chlorpromazine has been described in a brain-damaged child. ${ }^{3}$ Our patient had been a forceps delivery and had had several seizures as a child, but we have found no report of persistent dystonic side effects occurring in patients with minimal epilepsy. Protracted choreathetosis occurred in one patient after treatment with depot flupenthixol, but in this case only mild dystonia and no myoclonus was reported. ${ }^{4}$ Flupenthixol has been suggested to be the depot preparation most likely to cause generalised chorea, but there is no evidence to suggest that it induces other extrapyramidal disorders more often than similar preparations. ${ }^{5}$

The development of involuntary movements in this case were clearly associated with the administration of depot flupenthixol. We believe that it is important to draw attention to this complication of treatment; as our case suggests, patients with a history of birth trauma or childhood convulsions may be particularly at risk.

${ }^{1}$ Inoue F. Adverse reactions of antipsychotic drugs. Drug Intelligence and Clinical Pharmacy $1979 ; 13: 198-208$.

${ }^{2}$ Angle CR, McIntire MS, Zetterman R. CNS symptoms in childhood poisoning. Clin Toxicol 1968;1:19-29.

${ }^{3}$ Angle CR, McIntire MS. Persistent dystonia in a brain damaged child after ingestion of a phenothiazine. Paediatric Pharmacology and Therapeutics $1968 ; 73: 124-6$.

${ }^{4}$ Gibson AC. Depot injections and tardive dyskinesia. Br $\mathcal{F}$ Psychiat 1978; $133: 361-5$.

${ }^{5}$ Gibson AC. Questionnaire on severe tardive dyskinesia. Br 7 Psychiatry $1979 ; 134: 549-50$.

(Accepted 6 March 1981)

Neurological Unit, Middlesbrough General Hospital, Middlesbrough TS5 SA2

D J DICK, MRCP, registrar in neurology (present address: Regional Neurological Centre, Newcastle General Hospital, Newcastle upon Tyne NE4 6BE)

M SAUNDERS, FRCP, consultant neurologist

\section{Dangers of amiodarone and anticoagulant treatment}

An interaction between the antiarrhythmic drug amiodarone and the anticoagulant warfarin has not been reported previously. We describe a patient in whom the addition of amiodarone on two occasions led to dangerous increases in the anticoagulant effect of warfarin treatment. We confirmed the generality of the phenomenon in animal experiments.

\section{Case report}

A 57-year-old woman with rheumatoid arthritis who had had a cerebrovascular accident attributed to embolus associated with intermittent atrial fibrillation was treated with warfarin ( $3 \mathrm{mg}$ daily). Rhythm monitoring showed episodes of supraventricular tachycardia, sinus bradycardia, and atrial fibrillation with fast ventricular response. Sinoatrial disorder was diagnosed and a permanent pacemaker inserted. After trials of other antiarrhythmic drugs, treatment was started with amiodarone $200 \mathrm{mg}$ thrice daily, and on the same day the daily dose of warfarin was increased from $3 \mathrm{mg}$ to $5 \mathrm{mg}$ because the British corrected ratio of prothrombin times (BCR) was only 1.5 (figure). The BCR rose, and the patient developed gastrointestinal bleeding, requiring treatment with vitamin $K$.

One month later she was admitted to hospital elsewhere after another cerebrovascular accident, and treatment with warfarin was restarted. She had inadvertently stopped taking amiodarone three weeks before this admission. She was transferred back to our care and amiodarone was started again, but on this occasion warfarin was stopped on the same day because of the suspicion of possible interaction. The BCR, which had been steady at 2.5 for the preceding three days, rapidly rose to 4.5 after adding amiodarone (and stopping warfarin) and remained at this level until treated with vitamin $\mathrm{K}$ four days later (figure). 


\section{Experimental study}

Rabbits (2-2.5 kg New Zealand white) were treated with sodium warfarin (daily subcutaneous injection), the dosage being adjusted until the BCR was raised to a steady level (at dose $0.40 \div 0.04 \mathrm{mg}$ ), after which they were also treated with amiodarone chloride solution (Reckitt and Colman) $35 \mathrm{mg}$

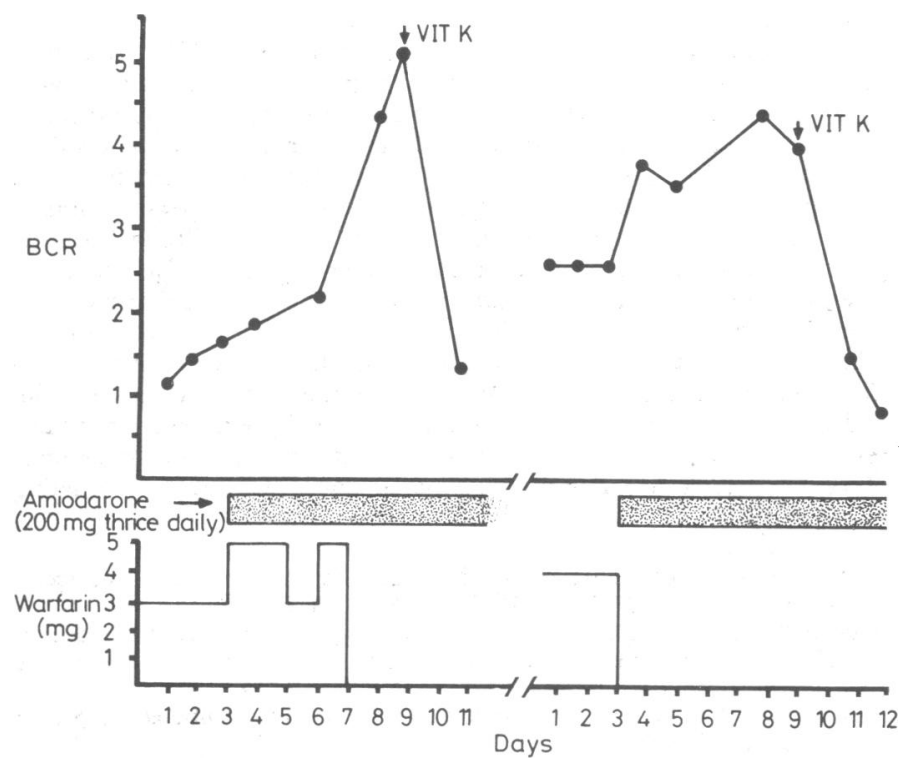

Effect of treatment with amiodarone on British corrected ratio of prothrombin times (BCR).

given in daily subcutaneous injections for four days. Venous blood samples (ear vein) were collected in HEPES-buffered trisodium citrate solution for measurement of prothrombin time, ${ }^{1}$ using both human and rabbit brain thromboplastin (Thromboplastin CAHS (UK) Ltd) and derivation of BCR. Results are given as mean $\pm S E$ and compared by paired Student's $t$ test. The addition of amiodarone resulted in a significant and striking increase in BCR from a stable level of $2 \cdot 6 \pm 0.38(n=5)$ before amiodarone, to $5.4 \pm 1.4$ on day $1,13.3 \pm 4.0$ on day 2 , and $6.2 \pm 0.59(n=3$, two rabbits having died from gastrointestinal haemorrhage) on day 3 , using human thromboplastin; or from $1.9 \pm 0.21$ to $4.0 \pm 1 \cdot 1,9.1 \pm 3.9$, and $3.6 \pm 0.45$ respectively, using rabbit thromboplastin.

\section{Comment}

Although not yet released for general use in Britain, amiodarone is widely used abroad and under hospital supervision in Britain. It has valuable antiarrhythmic properties ${ }^{2} 3$ associated with prolongation of action potential duration as well as slowing of action potential upstroke and thus conduction velocity. ${ }^{4}$ The need for special care in using amiodarone in combination with anticoagulant drugs has not been recognised. This case report and experimental study clearly indicate the need for great caution in this respect. The Committee for Safety in Medicine has in fact received some reports suggesting such an interaction (personal communication). Amiodarone is highly $(\geqslant 90 \%)$ protein bound in the blood. ${ }^{5} \mathrm{~A}$ possible explanation of the interaction is therefore that it displaces warfarin from protein-binding sites. Alternatively it could influence warfarin metabolism. This has important therapeutic implications for its clinical use in combination with many drugs.

We thank Dr J Giddings, Department of Haematology, University Hospital of Wales, Cardiff, for his help.

Requests for reprints should be addressed to: Professor A H Henderson, Department of Cardiology, Welsh National School of Medicine, Heath Park, Cardiff.

${ }^{1}$ Poller L. The British comparative thromboplastin: the use of the national thromboplastin reagent for uniformity of laboratory control of oral anticoagulation and expression of results. London: Association of Clinical Pathologists, 1970. (Broadsheet 71).

2 Rowland E, Krikler DM. Electrophysiological assessment of amiodarone in the treatment of resistant supraventricular arrhythmias. Br Heart $\mathcal{F}$ $1980 ; 44: 82-90$.

3 Ward DE, Camm AJ, Spurell RHJ. Clinical antiarrhythmic effect of amiodarone in patients with resistant paroxysmal tachycardia. Br Heart $\mathcal{f}$ $1980 ; 44: 91-5$.
${ }^{4}$ Singh BN, Vaughan Williams EM. The effect of amiodarone, a new anti-anginal drug, on cardiac muscle. Br F Pharmacol 1970;39:657.

${ }^{5}$ Charlier R, Deltour G, Bandine A, Chaillet F. Pharmacology of amiodorone. Arzneim Forsch 1968;18:1408-17.

(Accepted 11 March 1981)

Department of Cardiology, Welsh National School of Medicine, Cardiff CF4 4XN

A REES, BSC, $M B$, registrar

J J DALAL, MD, lecturer

P G REID, MB, senior house officer

A H HENDERSON, MB, FRCP, professor

Department of Pharmacology, Welsh National School of Medicine, Cardiff CF4 1XN

$M$ J LEWIS, PHD, MB, lecturer

\section{Emergency treatment of high blood pressure with oral atenolol}

Reduction of blood pressure within two hours with parenteral treatment is necessary in only a few well-defined clinical conditions, such as hypertensive encephalopathy and eclampsia. If pressure is reduced too quickly ischaemia of the heart, brain, or kidneys or blindness may ensue. ${ }^{123} \mathrm{~W}$ ith the exception of these dire emergencies, oral antihypertensive treatment may suffice, but even this may carry some hazard. ${ }^{1}$ We have used a single oral dose of the cardioselective beta-blocker atenolol in very severe hypertension in an attempt to control blood pressure smoothly and avoid rapid falls.

\section{Patients, methods, and results}

Patients with blood pressures exceeding $200 / 130 \mathrm{mg} \mathrm{Hg}$ or with malignant hypertension were treated with $100 \mathrm{mg}$ atenolol by mouth in a single dose. Patients in whom beta-blockers were contraindicated or in whom we suspected a phaeochromocytoma were excluded. Blood pressures were measured by the nursing staff, using standard sphygmomanometers and the fifth phase as diastolic pressure in the resting supine position for at least two hours before and for 12 hours after drug administration. "Pretreatment" blood pressure was taken as that reached when the pressure had stabilised after at least two hours of bed rest.

We studied eight men and two women. All were Caucasians, and their mean age was 46 (range 15-62 years). Nine had malignant hypertension, and only one was receiving treatment. There was a mean fall in pressure of $56 \mathrm{~mm} \mathrm{Hg}$ systolic and $40 \mathrm{~mm} \mathrm{Hg}$ diastolic over 12 hours. No side effects were encountered, and blood-pressure control was achieved smoothly without precipitous drops (table). Nine subjects had normal excretion urograms, serum electrolyte concentrations, and 24-hour urinary output of metanephrines. The remaining patient had evidence of renal artery stenosis on excretion urography.

Reduction of blood pressure in 10 patients after oral atenolol. Figures are means $\pm S D$

\begin{tabular}{|c|c|c|c|c|c|c|}
\hline & \multirow{2}{*}{$\begin{array}{l}1 \text { st } \\
\text { baseline } \\
\text { reading }\end{array}$} & \multicolumn{5}{|c|}{ Time in hours after dose } \\
\hline & & 0 & 2 & 4 & 8 & 12 \\
\hline $\begin{array}{l}\text { Systolic blood pressure } \\
\text { Diastolic blood pressure }\end{array}$ & $\begin{array}{l}\ldots 230 \pm 14 \\
\cdots 150 \pm 23\end{array}$ & $\begin{array}{l}224 \pm 17 \\
149 \pm 19\end{array}$ & $\begin{array}{l}214 \pm 14 \\
138 \pm 20\end{array}$ & $\begin{array}{l}200 \pm 21 \\
130 \pm 20\end{array}$ & $\begin{array}{l}193 \pm 25 \\
120 \pm 25\end{array}$ & $\begin{array}{l}176 \pm 22 \\
111 \pm 16\end{array}$ \\
\hline
\end{tabular}

\section{Comment}

Atenolol is rapidly absorbed after oral administration ${ }^{4}$ and is therefore suitable for patients who require rapid reduction of blood pressure. Other studies have shown that labetalol given by mouth is adequate for severe and accelerated hypertension, ${ }^{5}$ and we have found that a beta-blocker alone appears to have an adequate hypotensive effect in malignant hypertension. The prolonged antihypertensive effect of atenolol provides a further advantage in that subsequent doses need not be given for 12-18 hours, though all the present patients subsequently required further drugs to control their blood pressure. Blood pressures after 12 hours were not normal, but a gradual reduction is more important than to achieve this. We 